\title{
Maternal Occupational Oil Mist Exposure and Birth Defects, National Birth Defects Prevention Study, 1997-2011
}

\author{
Miriam Siegel ${ }^{1,2}{ }^{*}$, Carissa M. Rocheleau ${ }^{2}$, Candice Y. Johnson ${ }^{2} \mathbb{D}$, Martha A. Waters ${ }^{3}$, \\ Christina C. Lawson ${ }^{2}$, Tiffany Riehle-Colarusso ${ }^{4}$, Jennita Reefhuis ${ }^{4}$ \\ and The National Birth Defects Prevention Study ${ }^{4}$ \\ 1 Epidemic Intelligence Service, Center for Surveillance, Epidemiology and Laboratory Services, Atlanta, \\ GA 30329, USA \\ 2 Division of Surveillance, Hazard Evaluations, and Field Studies, National Institute for Occupational Safety \\ and Health, Cincinnati, OH 45226, USA; crocheleau@cdc.gov (C.M.R.); cyjohnson@cdc.gov (C.Y.J.); \\ clawson@cdc.gov (C.C.L.) \\ 3 Division of Applied Research and Technology, National Institute for Occupational Safety and Health, \\ Cincinnati, OH 45226; mwaters@cdc.gov \\ 4 Division of Congenital and Developmental Disorders, National Center on Birth Defects and Developmental \\ Disabilities, Atlanta, GA 30329, USA; tja4@cdc.gov (T.R.-C.); nzr5@cdc.gov (J.R.); \\ wrm9@cdc.gov (T.N.B.D.P.S.) \\ * Correspondence: msiegel@cdc.gov; Tel.: +1-513-841-4517
}

Received: 28 February 2019; Accepted: 3 May 2019; Published: 4 May 2019

check for updates

\begin{abstract}
Workers in various industries can be exposed to oil mists when oil-based fluids are aerosolized during work processes. Oil mists can be inhaled or deposited on the skin. Little research exists on the reproductive effects of oil mist exposure in pregnant workers. We aimed to investigate associations between occupational oil mist exposure in early pregnancy and a spectrum of birth defects using data from 22,011 case mothers and 8140 control mothers in the National Birth Defects Prevention Study. In total, 150 mothers were rated as exposed. Manufacturing jobs, particularly apparel manufacturing, comprised the largest groups of exposed mothers. Mothers of infants with septal heart defects (odds ratio (OR): 1.8, 95\% confidence interval (CI): 1.0-3.3), and especially perimembranous ventricular septal defects (OR: 2.5, CI: 1.2-5.2), were more likely to be occupationally exposed to oil mists in early pregnancy than control mothers; and their rater-estimated cumulative exposure was more likely to be higher. This was the first U.S. study evaluating associations between oil mist exposure and a broad spectrum of birth defects. Our results are consistent with previous European studies, supporting a potential association between oil-based exposures and congenital heart defects. Further research is needed to evaluate the reproductive effects of occupational oil mist exposure.
\end{abstract}

Keywords: birth defects; congenital heart defects; oil mists; occupational exposure

\section{Introduction}

In 1999, the National Institute for Occupational Safety and Health (NIOSH) investigated a cluster of severe congenital heart defects (CHDs) among infants of three male employees at a steel strip manufacturing facility [1]. Two of the employees cut and packaged steel; both of their infants had hypoplastic right hearts with interrupted aortic arches. The third employee worked as a janitor and spent time in different parts of the plant, but spent the most time in the department where metals were electroplated; his infant had hypoplastic left heart syndrome. All three infants were born in 1998 in 
addition to 11 other infants born to plant workers that year, resulting in a prevalence of severe CHDs of $21 \%$, compared to an expected prevalence of $0.01-0.04 \%$ for this geographic area [2].

Further investigation into births among the plant employees identified an infant with Tetralogy of Fallot born to a male plant worker in 1993. A subsequent review of insurance claims for 89 births to plant employees from 1994-2000 did not reveal any other severe CHDs, although 4 cases of atrial septal defects were identified ( 3 born to male employees and 1 to a female employee whom worked at the plant during pregnancy), along with 2 cases of cleft lip and palate, and 1 case of hydrocephaly (all among the offspring of male employees). This resulted in a major birth defect prevalence of $11 \%$ in the years 1994-2000. An extensive exposure assessment was conducted at the plant, but no causative agent was identified to explain the high prevalence of birth defects. While nickel was the only exposure for which measurements exceeded recommended occupational exposure levels during the investigation, workers were also exposed to copper, iron, zinc dust, a trade secret metal, and oil mists.

Oil mists arise from the use of mineral oil, a petroleum refining distillate, as either a lubricant or non-lubricant. Lubricants include metalworking fluids, engine oils, hydraulic fluids, and gear oils. Non-lubricant processes generating oil mists include agricultural oil sprays and printing ink [3]. Metalworking fluids, one of the most common sources of oil mist exposures, are used to facilitate metal cutting, inhibit rust, and lubricate and cool machinery components. They are complex mixtures that often include mineral oils, biocides, and rust inhibitors. Metalworking fluids can become aerosolized through the high shear force of moving parts, excessive heating, or spray application. The resulting oil mists can be inhaled or deposited on employees' skin or clothing $[4,5]$. One potential mechanism by which occupational exposures among male employees might affect the risk of birth defects is through take-home exposure: when employees bring contaminated clothes, shoes, or work tools into their homes or automobiles where their family members (e.g., pregnant partners) can then be exposed [1]. Although not much is known about the paternal or maternal reproductive toxicity of oil mist exposure, it is possible that direct maternal occupational exposure to oil mists could have the same, or greater, effect as take-home exposure.

A majority of research on the human health effects of oil mist exposure has been related to dermal and respiratory effects and cancer [4-7]. Few studies have evaluated the relationship between oil mist exposure and birth defects. One study of paternal occupational exposures from England found no adverse association between oil mists and neural tube defects (22 exposed cases) [8]. On the other hand, occupational mineral oil exposure was found to be more prevalent among mothers of infants with CHDs (16 exposed cases) than among mothers of control infants in Finland [9], with a strong association observed with the coarctation of the aorta in a subsequent analysis (4 exposed cases) [10]. Another European study found elevated odds for occupational exposure to mineral oils in mothers of infants born with cleft palate, although the association was not statistically significant and there were only 3 exposed case mothers [11].

The current study aimed to investigate associations between estimated maternal occupational oil mist exposure during pregnancy and birth defects using population-based case-control data. Additionally, we sought to identify industries and occupations in which pregnant women were exposed to oil mists and the frequency of birth defects occurring within these industries and occupations.

\section{Materials and Methods}

\subsection{Study Design}

Data were analyzed from the National Birth Defects Prevention Study (NBDPS), a multi-center, population-based case-control study of birth defects. The NBDPS design and methods have been described elsewhere [12,13]. Briefly, the birth defects surveillance and research programs in 10 states (Arkansas, California, Georgia, Iowa, Massachusetts, New Jersey, New York, North Carolina, Texas, and Utah) conducted case ascertainment of infants and fetuses with major structural, non-chromosomal birth defects. Cases and controls were included for births on or after October 1, 1997, and with 
estimated dates of delivery on or before December 31, 2011. Each study site obtained institutional review board approval. Clinical geneticists reviewed each case to exclude potential syndromic cases and to classify cases as being isolated (no other major birth defects) or having multiple major birth defects [14]. All CHD cases were confirmed by echocardiography, cardiac catheterization, surgery, or autopsy. Information was reviewed by expert pediatric clinicians to classify CHD cases as simple (one single CHD or a well-defined constellation of defects recognized as one entity [15,16]), associated (common, uncomplicated combinations of CHD), or complex (three or more distinct defects). Both CHD and non-heart defects were classified as isolated (diagnosed with only one major defect) or multiple (two or more major defects occurring in different organ systems) [13]. Controls were drawn from a random sample of live births without major structural defects in the same study regions and were identified from hospital delivery logs or vital records.

Mothers completed a computer-assisted telephone interview between 6 weeks and 2 years after the estimated date of delivery. The interview included questions about various lifestyle and behavioral exposures during pregnancy, reproductive history, and occupation. This analysis included all case and control mothers who participated in NBDPS and reported working at some point during the three months before conception through the end of the pregnancy.

\subsection{Outcomes}

To be included in this analysis, we required a birth defect grouping to have at least 100 total isolated cases (simple, isolated cases for CHDs) and at least three isolated case mothers exposed to oil mists in early pregnancy. When a detailed birth defect phenotype did not meet this sample size criterion, it was grouped into a larger anatomical group if possible. Only simple isolated cases of birth defects were assessed in attempts to identify specific exposure effects for homogeneous outcome categories.

\subsection{Exposure}

Retrospective exposure assessment for oil mists was completed for maternal jobs held for one month or more during the three months before conception through the end of pregnancy for all births. A description of the exposure assessment methods has been described elsewhere [17]. In brief, each job was assigned a 1997 North American Industry Classification System (NAICS) and 2000 Standard Occupational Classification (SOC) code from information about work activities provided in the interview [18]. Two trained industrial hygienists reviewed the NAICS and SOC codes in addition to the occupational description (e.g., job title, descriptions of the company's product/service, main job activities/duties, chemicals/substances handled, machines used on the job, and work frequency/duration) for jobs reported by mothers to assign (1) whether mothers were likely exposed to oil mists (yes/no) (including any route of exposure; i.e., inhalation, dermal, and/or ingestion) and (2) scores for estimated intensity, frequency, and rater confidence of exposure. All discrepancies were resolved by a consensus conference with a third rater. Intensity scores were quantitatively mapped to a midpoint of an intensity score category $\left(\mathrm{in} \mu \mathrm{g} / \mathrm{m}^{3}\right.$ ). Cumulative exposure in the periconceptional period (defined as the month prior to conception through the first three months of pregnancy) was estimated and defined as intensity $\left(\mu \mathrm{g} / \mathrm{m}^{3}\right)$ multiplied by frequency (percentage of work hours exposed) multiplied by the typical hours per week worked at the job during this period, and the number of weeks the job was held during the periconceptional period. The resulting cumulative exposure estimate, in $\mu \mathrm{g} / \mathrm{m}^{3}$-hours, is to be interpreted as a tool for comparison rather than a quantitative exposure measurement. If mothers held multiple jobs during the exposure window, job-specific exposure was summed across all jobs. Coders and industrial hygienists were blinded to the mothers' case-control status.

The current analysis considered mothers exposed if at least one job held at any point during early pregnancy (i.e., one month before conception through the third month of pregnancy) was rated as having possible oil mist exposure. This period captures periods of egg maturation, fertilization and implantation, and embryo-fetal development (including organogenesis) that are considered 
most vulnerable to teratogens. Each exposed mother was categorized as having high exposure or low exposure based on a cutoff defined by the median estimated oil mist level among exposed control mothers.

\subsection{Statistical Analysis}

We first described the demographic characteristics among case and control mothers. Frequencies and percentages were calculated for the study site, mother's smoking status in early pregnancy, maternal age at delivery (under 20, 20-34, and 35 years or older), mother's body mass index (BMI) (underweight $\left(<18.5 \mathrm{~kg} / \mathrm{m}^{2}\right)$, normal weight $\left(18.5-<24 \mathrm{~kg} / \mathrm{m}^{2}\right)$, overweight $\left(25-<30 \mathrm{~kg} / \mathrm{m}^{2}\right)$, and obese $\left(>30 \mathrm{~kg} / \mathrm{m}^{2}\right)$ ), maternal education (less than high school vs. high school or more), and maternal race/ethnicity (non-Hispanic white vs. non-white). P-values were calculated using chi-square tests to assess differences between cases and controls, excluding missing values.

To estimate associations between oil mist exposure in early pregnancy and individual isolated birth defects, we used logistic regression to estimate the crude odds ratios and $95 \%$ confidence intervals. Oil mist exposure was analyzed as a binary variable (i.e., any vs. none) and as a categorical variable (i.e., below and above the median cumulative exposure in controls vs. no exposure). Adjusted odds ratios and $95 \%$ confidence intervals were calculated using multivariable logistic regression controlling for the study site and smoking status a priori based on the potential variability in case and control selection across sites and the evidence for smoking as a risk factor for a spectrum of birth defects [19]. Other covariates were adjusted for in exploratory models a priori to examine potential confounding effects, but did not meet the criteria for inclusion in the final adjusted model (i.e., they were not significant in the model and/or did not produce at least a 10\% change in the effect estimate of the main effect), including maternal age, BMI, education, and race/ethnicity. To further evaluate the categorical exposure variable for dose-response relationships, we calculated the $p$-trend values by treating the categorical variable as continuous in adjusted logistic regression models. A sensitivity analysis was conducted to assess how the inclusion of infants with multiple birth defects affected the estimates associated with the binary exposure variable.

A descriptive analysis was conducted to describe the most prevalent industries and occupations (I\&Os) held by mothers who were occupationally exposed to oil mists in early pregnancy. Job I\&Os were grouped according to NAICS and SOC codes at the 3-digit level. I\&Os were included where at least 3 mothers were exposed in the early pregnancy. Jobs without enough information available to assign an industry group (i.e., NAICS "31-33"-Manufacturing) were excluded from the descriptive analysis of industry groups ( $n=16$ jobs held by 10 case and 6 control mothers that were all unexposed); all jobs had adequate information to assign an occupation group. Within each $I \& O$ group, we calculated the number of mothers who were classified as exposed to oil mists in early pregnancy and the median estimated cumulative exposure among exposed mothers. Among the exposed mothers in each I\&O group, we calculated the number of total exposed cases, exposed simple isolated CHDs, and exposed isolated non-heart defects. Some mothers were included in multiple I\&O groups if they held multiple jobs ( $n=24$ mothers; none were exposed to oil mists during early pregnancy in more than 1 job).

All analyses were conducted in SAS version 9.4 software (SAS Institute, Cary, NC, USA).

\section{Results}

After excluding 24 jobs due to missing or insufficiently detailed job descriptions for exposure assessment, there were 30,151 women working a total of 35,400 jobs included in this analysis. There were 22,011 case families and 8140 control families. One hundred and fifty women were rated as possibly exposed to oil mists in early pregnancy (108 case families, 42 control families) and 30,001 women were rated as unexposed (21,903 case families, 8098 control families). The median estimated exposure was $193.1 \mu \mathrm{g} / \mathrm{m}^{3}$-hours (range: $4.5-2160.0$ ) in all exposed mothers. The median estimated exposure in exposed controls was $212.5 \mu \mathrm{g} / \mathrm{m}^{3}$-hours (range: $4.5-1071.4$ ), leaving 78 and 72 mothers with low and high estimated exposure, respectively. 
The demographic characteristics of cases and controls are shown in Table 1. Although some differences in demographic characteristics between cases and controls were statistically significant, the proportions of the study site, maternal smoking status, age at delivery, BMI, education, and race/ethnicity did not vary in a substantially meaningful way between cases and controls. Demographic characteristics of mothers exposed and unexposed to oil mists in early pregnancy are presented in the Supplementary Materials (Table S1).

Table 1. The demographic characteristics of case mothers of infants with isolated birth defects and control mothers of infants without birth defects, NBDPS, 1997-2011.

\begin{tabular}{|c|c|c|c|c|c|}
\hline \multirow{2}{*}{ Characteristic } & \multicolumn{2}{|c|}{ Cases $(n=22,011)$} & \multicolumn{2}{|c|}{ Controls $(n=8140)$} & \multirow{2}{*}{$p$-Value } \\
\hline & $n$ & $\%$ & $n$ & $\%$ & \\
\hline Study site & & & & & $<0.001$ \\
\hline Arkansas & 3021 & 13.7 & 1044 & 12.8 & \\
\hline California & 2239 & 10.2 & 744 & 9.1 & \\
\hline Georgia & 2524 & 11.5 & 909 & 11.2 & \\
\hline Iowa & 2426 & 11.0 & 1062 & 13.1 & \\
\hline Massachusetts & 3045 & 13.8 & 1084 & 13.3 & \\
\hline New Jersey & 1204 & 5.5 & 407 & 5.0 & \\
\hline New York & 1634 & 7.4 & 729 & 9.0 & \\
\hline North Carolina & 1745 & 7.9 & 690 & 8.5 & \\
\hline Texas & 1912 & 8.7 & 737 & 9.1 & \\
\hline Utah & 2261 & 10.3 & 734 & 9.0 & \\
\hline Smoking status in early pregnancy & & & & & $<0.001$ \\
\hline No smoking & 17,427 & 79.2 & 6602 & 81.1 & \\
\hline Any smoking & 4568 & 20.8 & 1536 & 18.9 & \\
\hline Missing & 16 & & 2 & & \\
\hline Maternal age at delivery (years) & & & & & 0.04 \\
\hline$<20$ & 1642 & 7.5 & 565 & 6.9 & \\
\hline $20-34$ & 16,917 & 76.9 & 6366 & 78.2 & \\
\hline $35+$ & 3452 & 15.7 & 1209 & 14.9 & \\
\hline Body mass index & & & & & $<0.001$ \\
\hline Underweight & 1031 & 4.7 & 372 & 4.6 & \\
\hline Normal & 11,050 & 50.2 & 4298 & 52.8 & \\
\hline Overweight & 5005 & 22.7 & 1837 & 22.6 & \\
\hline Obese & 4372 & 19.9 & 1452 & 17.8 & \\
\hline Missing & 553 & & 181 & & \\
\hline Maternal education & & & & & 0.002 \\
\hline Less than high school & 2456 & 11.2 & 805 & 9.9 & \\
\hline High school or more & 19,513 & 88.8 & 7321 & 90.1 & \\
\hline Missing & 42 & & 14 & & \\
\hline Maternal race/ethnicity & & & & & 0.45 \\
\hline Non-Hispanic white & 14,057 & 63.9 & 5161 & 63.4 & \\
\hline Non-white & 7951 & 36.1 & 2979 & 36.6 & \\
\hline Missing & 3 & & 0 & & \\
\hline
\end{tabular}

Nineteen birth defect groups had a sufficient sample size for analysis $(\geq 100$ simple, isolated cases with at least 3 exposed to oil mists), including any CHD, eight specific CHD phenotypes, and 10 non-heart defects. Table 2 displays the crude and adjusted associations between estimated oil mist exposure in early pregnancy and individual birth defects. Although not statistically significant, mothers of infants born with any CHD had 1.3 times higher odds of being exposed than control mothers (95\% CI: 0.8-2.0). Five out of eight specific CHD phenotypic groups (i.e., CHD groups excluding "any CHD") displayed odds ratios above 1, although only two reached statistical significance. Crude results showed that oil mist exposure was significantly associated with all septal defects (OR: 2.0; 95\% CI: 1.1-3.4), and specifically, perimembranous ventricular septal defects (VSD) (OR: 2.7; 95\% CI: 1.3-5.6). 
There were no statistically significant associations between oil mist exposure and non-heart defects. Esophageal atresia was the only non-heart defect for which there was an odds ratio above 1 (OR: 2.4; 95\% CI: 0.7-7.9). After adjusting for additional a priori covariates, estimates were similar or attenuated (Table 2). Although the main analyses were restricted to simple isolated cases to limit heterogeneity, we conducted a sensitivity analysis including both simple, isolated and multiple defects. This sensitivity analysis did not reveal any new associations; odds ratios were either very similar or slightly attenuated (Table S2).

Table 2. The crude and adjusted associations between any maternal occupational oil mist exposure in early pregnancy and (simple) isolated birth defects, NBDPS, 1997-2011.

\begin{tabular}{|c|c|c|c|c|c|c|c|}
\hline \multirow{2}{*}{ Defect } & \multirow{2}{*}{$\begin{array}{c}\text { Isolated } \\
\text { Cases } \\
n\end{array}$} & \multirow{2}{*}{$\begin{array}{c}\text { Controls } \\
n\end{array}$} & \multirow{2}{*}{$\begin{array}{c}\text { Exposed } \\
\text { Cases }^{1} \\
n\end{array}$} & \multicolumn{2}{|c|}{ Crude } & \multicolumn{2}{|c|}{ Adjusted $^{2}$} \\
\hline & & & & $\mathrm{OR}^{3}$ & $95 \% \mathrm{CI}$ & $\mathrm{OR}^{3}$ & $95 \%$ CI \\
\hline \multicolumn{8}{|l|}{ Congenital heart defects (CHD) } \\
\hline Any CHD & 5481 & 8140 & 36 & 1.27 & $(0.82,1.99)$ & 1.24 & $(0.79,1.95)$ \\
\hline Conotruncal defects & 1299 & 8140 & 5 & 0.75 & $(0.29,1.89)$ & 0.76 & $(0.30,1.94)$ \\
\hline Tetralogy of Fallot & 708 & 8140 & 3 & 0.82 & $(0.25,2.65)$ & 0.85 & $(0.26,2.75)$ \\
\hline LVOTO defects & 1068 & 8140 & 5 & 0.91 & $(0.36,2.30)$ & 0.95 & $(0.37,2.41)$ \\
\hline RVOTO defects & 996 & 8140 & 7 & 1.36 & $(0.61,3.05)$ & 1.30 & $(0.58,2.92)$ \\
\hline Pulmonary valve stenosis & 744 & 7856 & 6 & 1.55 & $(0.66,3.66)$ & 1.44 & $(0.61,3.44)$ \\
\hline Septal defects & 1789 & 8140 & 18 & 1.96 & $(1.13,3.41)$ & 1.84 & $(1.05,3.25)$ \\
\hline Perimembranous VSD & 647 & 8140 & 9 & 2.72 & $(1.32,5.61)$ & 2.51 & $(1.21,5.20)$ \\
\hline ASD secundum or ASD NOS & 1005 & 8140 & 7 & 1.35 & $(0.61,3.02)$ & 1.29 & $(0.57,2.94)$ \\
\hline \multicolumn{8}{|l|}{ Non-heart defects } \\
\hline Neural tube defects & 1224 & 8140 & 5 & 0.79 & $(0.31,2.00)$ & 0.77 & $(0.30,1.94)$ \\
\hline Spina bifida & 732 & 8140 & 3 & 0.79 & $(0.25,2.57)$ & 0.77 & $(0.24,2.51)$ \\
\hline Oral clefts & 2763 & 8047 & 11 & 0.76 & $(0.39,1.48)$ & 0.81 & $(0.42,1.58)$ \\
\hline Cleft palate only & 901 & 8047 & 3 & 0.64 & $(0.20,2.06)$ & 0.67 & $(0.21,2.16)$ \\
\hline Cleft lip with cleft palate & 1159 & 8047 & 5 & 0.83 & $(0.33,2.09)$ & 0.87 & $(0.34,2.22)$ \\
\hline Cleft lip without cleft palate & 703 & 8047 & 3 & 0.82 & $(0.25,2.64)$ & 0.89 & $(0.27,2.87)$ \\
\hline Esophageal atresia & 242 & 8140 & 3 & 2.42 & $(0.74,7.86)$ & 2.50 & $(0.76,8.18)$ \\
\hline Hypospadias & 1776 & 4157 & 7 & 0.82 & $(0.35,1.94)$ & 0.91 & $(0.38,2.21)$ \\
\hline Craniosynostosis & 1017 & 8140 & 4 & 0.76 & $(0.27,2.13)$ & 0.80 & $(0.28,2.23)$ \\
\hline Gastroschisis & 847 & 8140 & 3 & 0.69 & $(0.21,2.22)$ & 0.73 & $(0.22,2.39)$ \\
\hline
\end{tabular}

Table 3 shows the crude and adjusted associations between estimated cumulative oil mist exposure and individual birth defects. Many comparisons could not be reported due to an inadequate number of exposed case mothers. Dose-response patterns were observed between the estimated exposure level and septal defects, particularly for perimembranous VSDs ( $p$-trend $=0.02,0.01$, respectively). Mothers of infants with septal defects and specifically perimembranous VSDs were more likely to have high exposure than control mothers (OR 2.3, 95\% CI: 1.1-4.7; OR 2.9, 95\% CI: 1.1-7.7, respectively). No apparent dose-response patterns existed between the exposure level and non-heart defects. Results of the exposure level analyses did not change substantially when adjusting for the study site and smoking status (Table 3).

There were 10 industries and six occupations at the three-digit NAICS/SOC code level with at least three exposed case mothers (Table 4). The industries with the highest number of exposed mothers were machinery manufacturing $(n=27)$; apparel manufacturing $(n=24)$; and transportation equipment manufacturing $(n=18)$. The occupations with the highest number of exposed mothers were textile, apparel, and furnishings workers $(n=45)$; assemblers and fabricators $(n=35)$; and metal workers and plastic workers $(n=32)$. There were exposed simple isolated CHD cases in all industry and occupation groups assessed, and exposed isolated non-heart defect cases in all but one group (Table 4). 
Table 3. The crude and adjusted associations between estimated cumulative oil mist exposure level and (simple) isolated birth defects, NBDPS, $1997-2011$.

\begin{tabular}{|c|c|c|c|c|c|c|c|c|c|c|c|}
\hline \multirow{3}{*}{ Defect $^{1}$} & \multirow{3}{*}{$\begin{array}{c}\text { Low Exposure }^{2} \\
n \text { cases }\end{array}$} & \multirow{3}{*}{$\begin{array}{c}\text { High Exposure }^{2} \\
n \text { cases }\end{array}$} & \multicolumn{4}{|c|}{$\begin{array}{r}\text { Crude } \\
\end{array}$} & \multicolumn{4}{|c|}{ Adjusted $^{3}$} & \multirow{3}{*}{$p$-Trend ${ }^{2}$} \\
\hline & & & \multicolumn{2}{|c|}{ Low Exposure } & \multicolumn{2}{|c|}{ High Exposure } & \multicolumn{2}{|c|}{ Low Exposure } & \multicolumn{2}{|c|}{ High Exposure } & \\
\hline & & & OR & $95 \%$ CI & $\mathrm{OR}^{4}$ & $95 \%$ CI & OR & $95 \% \mathrm{CI}$ & $\mathrm{OR}^{4}$ & $95 \%$ CI & \\
\hline \multicolumn{12}{|l|}{ Congenital heart defects (CHD) } \\
\hline Any CHD & 17 & 19 & 1.26 & $(0.66,2.42)$ & 1.28 & $(0.70,2.38)$ & 1.21 & $(0.63,2.32)$ & 1.28 & $(0.69,2.37)$ & 0.35 \\
\hline Septal defects & 7 & 11 & 1.60 & $(0.68,3.79)$ & 2.29 & (1.11, 4.72) & 1.37 & $(0.57,3.29)$ & 2.34 & $(1.11,4.91)$ & 0.02 \\
\hline Perimembranous VSD & 4 & 5 & 2.54 & $(0.87,7.45)$ & 2.89 & $(1.09,7.65)$ & 2.17 & $(0.73,6.43)$ & 2.84 & $(1.06,7.59)$ & 0.01 \\
\hline \multicolumn{12}{|l|}{ Non-heart defects } \\
\hline Oral clefts & 5 & 6 & 0.73 & $(0.27,1.94)$ & 0.79 & $(0.32,1.96)$ & 0.80 & $(0.30,2.14)$ & 0.82 & $(0.33,2.02)$ & 0.56 \\
\hline Cleft lip with or without cleft palate & 3 & 5 & 0.65 & $(0.19,2.18)$ & 0.98 & $(0.37,2.60)$ & 0.72 & $(0.21,2.43)$ & 1.02 & $(0.38,2.71)$ & 0.85 \\
\hline
\end{tabular}

${ }^{1}$ Only defects with $\geq 3$ cases with low exposure and high exposure are presented; ${ }^{2} n=20$ controls with low exposure and $n=22$ controls with high exposure for all defects presented; ${ }^{3}$ Adjusted for study site and smoking status (observations with missing smoking status excluded); ${ }^{4}$ Bold font indicates statistically significant associations. OR: Odds ratio; CI: Confidence interval; VSD: Ventricular septal defect.

Table 4. The number of mothers occupationally exposed to oil mists in early pregnancy and cases by industry and occupation, NBDPS, $1997-2011$.

\begin{tabular}{|c|c|c|c|c|c|c|c|}
\hline \multirow{2}{*}{ 3-Digit Code } & \multirow{2}{*}{ Title } & \multicolumn{2}{|c|}{$\begin{array}{c}\text { Workers Exposed to Oil Mists in Early } \\
\text { Pregnancy }{ }^{1}\end{array}$} & \multirow{2}{*}{$\begin{array}{c}\text { Median Exposure } \\
\left(\mu \mathrm{g} / \mathrm{m}^{3} \text {-hours }\right)\end{array}$} & \multirow{2}{*}{$\begin{array}{c}\text { Exposed Cases }^{3} \\
n\end{array}$} & \multirow{2}{*}{$\begin{array}{c}\begin{array}{c}\text { Exposed Simple } \\
\text { Isolated CHDs }\end{array} \\
n\end{array}$} & \multirow{2}{*}{$\begin{array}{c}\text { Exposed Isolated } \\
\text { Non-Heart Defect } \\
n\end{array}$} \\
\hline & & $n$ & $(\%)^{2}$ & & & & \\
\hline & Industry (NAICS) & & & & & & \\
\hline 313 & Textile Mills & 5 & (12.5) & 212.6 & 4 & NR & NR \\
\hline 314 & Textile Product Mills & 12 & (23.5) & 191.3 & 10 & NR & 3 \\
\hline 315 & Apparel Manufacturing & 24 & (19.7) & 180.7 & 20 & 8 & 9 \\
\hline 326 & Plastics and Rubber Products Manufacturing & 12 & $(10.8)$ & 210.4 & 10 & 5 & NR \\
\hline 331 & Primary Metal Manufacturing & 3 & $(11.5)$ & 191.3 & 3 & NR & NR \\
\hline 332 & Fabricated Metal Product Manufacturing & 15 & (15.8) & 287.0 & 12 & 7 & 4 \\
\hline 333 & Machinery Manufacturing & 27 & (21.1) & 258.3 & 19 & 6 & 10 \\
\hline 335 & Electrical Equipment, Appliance, and Component Manufacturing & 9 & $(10.1)$ & 142.8 & 7 & 3 & 3 \\
\hline 336 & Transportation Equipment Manufacturing & 18 & (14.5) & 255.8 & 14 & NR & 8 \\
\hline \multirow[t]{2}{*}{339} & Miscellaneous Manufacturing & 6 & (3.3) & 191.3 & 4 & NR & 3 \\
\hline & Occupation (SOC) & & & & & & \\
\hline 511 & Supervisors, Production Workers & 5 & $(8.9)$ & 215.2 & 4 & NR & NR \\
\hline 512 & Assemblers and Fabricators & 35 & $(21.0)$ & 191.3 & 25 & 6 & 13 \\
\hline 514 & Metal Workers and Plastic Workers & 32 & $(36.8)$ & 321.4 & 26 & 9 & 12 \\
\hline 516 & Textile, Apparel, and Furnishings Workers & 45 & (17.1) & 191.3 & 32 & 10 & 13 \\
\hline 519 & Other Production Occupations & 19 & (3.5) & 191.3 & 12 & 4 & 5 \\
\hline 537 & Material Moving Workers & 5 & (1.0) & 191.3 & 3 & NR & 0 \\
\hline
\end{tabular}

${ }^{1}$ No exposed workers fall into more than one industry or occupation category; ${ }^{2}$ The percentage of workers in an industry or occupation group that were exposed to oil mists in early pregnancy; ${ }^{3}$ Total birth defect cases exposed to oil mists in early pregnancy; NR: Not reportable $(n<3)$. 


\section{Discussion}

This analysis found that mothers whose infants were born with septal heart defects, and especially perimembranous VSDs, were more likely to be exposed to oil mists during the period of one month before conception through the third month of pregnancy than control mothers; and there was some indication of a dose-response effect.

Although the small number of mothers exposed to oil mists limited statistical comparisons, the overall pattern of findings is interesting: five out of eight CHD phenotypic groups showed elevated odds ratios, while only one of 10 non-heart defects displayed an elevated odds ratio. If the results were due to chance, an approximately equal distribution of positive and inverse estimates would likely be observed for CHDs and non-heart defects. However, the observed pattern, in addition to the abovementioned significant associations, indicates a possible association between oil mist exposure and CHDs. Nine non-heart defects showed odds ratios less than 1 . However, none of those estimates were statistically significant, and further dose-response analyses of non-heart defects with adequate sample size revealed estimates moved closer to the null with higher exposure, suggesting the absence of potential protective associations.

The birth defects found in association with oil mist exposure in the current analysis are similar, but not identical, to those exhibited in the birth defects cluster investigated by NIOSH in 1999 [1], namely CHDs and specifically septal heart defects. The NIOSH report found four cases of atrial septal defects during the time period of 1994-1999. The current study did not find a significant association with atrial septal defects. There were inadequate exposed sample sizes for other specific defects found in the cluster to analyze with NBDPS data, such as hypoplastic right/left heart syndrome. The observed associations between maternal oil mist exposure and CHDs are consistent with the hypothesis that birth defects among male employees working with oil mists, like those investigated by NIOSH, could occur due to take-home exposure [1]; however, we cannot rule out both a maleand female-mediated association. Exposure assessment for paternal occupational oil mist exposure was not conducted in NBDPS, in part because paternal job descriptions are only available by proxy reports made by mothers. Although proxy job descriptions often provide sufficient detail for coding for many exposures (for example, pesticides $[20,21]$ ), proxy respondents often have difficulty providing sufficient detail for unfamiliar job tasks [22] such as work in a factory (where oil mist exposure is most common in male workers).

Our findings are similar to those of studies from Finland that found maternal occupational exposure to mineral oil products [4], to be associated with CHDs, particularly the coarctation of the aorta $[9,10]$. Although the current sample size was too small to study coarctation of the aorta specifically, we found a statistically significant association between oil mist exposure and VSD, a defect that may occur in association with coarctation of the aorta [23]. Additionally, there was a pattern of positive associations between oil mist exposure and most CHDs analyzed. Another study found non-significantly elevated odds for occupational mineral oil exposure in mothers of infants born with oral clefts [11]. We found no association between oil mist exposure and oral clefts. However, the sample sizes in both analyses were very limited.

In the general working population, a majority of workers exposed to oil mists work in machinery, metal fabrications, and transportation equipment industries and are male [6,24]. However, maternal occupations in manufacturing have been associated with oral clefts [11,25] and anotia [18]; and maternal occupations in metalworking with amniotic band defects [18]. In the current analysis, a large portion of exposed mothers worked in textile and apparel production industries, which have a female-dominated workforce [24,26], and are not obviously associated with oil mist exposure. Workers in textile and apparel production industries can be exposed to oil mists used to lubricate machinery. Friction and heat from the machines can cause the fluids to aerosolize and be inhaled by or deposited on the skin of the operator. Studies have found maternal occupations related to textiles and apparel manufacturing to be related to birth defects such as atrioventricular septal defects [18], oral clefts [27,28], and hypospadias [29]. A 1997 NIOSH investigation of a range of symptoms reported by employees at 
a clothing manufacturing company found elevated rates of birth defects, stillbirths, and premature births in women who were pregnant while working at the company [30]. Most textile and apparel production workers would likely have oil mist exposure below the recommended exposure limits of $5 \mathrm{mg} / \mathrm{m}^{3}$ as a time-weighted average [31,32]. However, these limits are based on health effects in healthy adults (primarily males) and might be insufficient to protect a pregnant worker or her fetus.

Most industrial exposures are mixed, making it difficult to identify specific exposures that may be risk factors for birth defects. As an example, metalworking fluids are a mixture of chemicals which vary by use [6], including alkyl phenolic surfactants [33], solvent degreasers [34], and polycyclic aromatic hydrocarbons [4]. Alkylphenolic compounds are potential endocrine disruptors [35]. A European meta-analysis found that maternal occupational exposure to alkylphenolic compounds related to higher odds of term low birthweight [36], and another study found a positive association with hypospadias [29]. Maternal occupational exposure to trichloroethylene was found to be related to cleft palates in a European case-control study [11]. Polycyclic aromatic hydrocarbons have been shown to relate to neural tube defects [37-39] and gastroschisis [40]. There are also potential genotoxic properties of some metalworking fluids [41]. Information on these and other chemical and non-chemical risk factors for birth defects were either not available to include in this study or our sample size limited our ability to adjust for them.

This study is the first analysis, to the authors' knowledge, of associations between estimated occupational exposure to oil mists and a broad spectrum of birth defects. It is also the first analysis of health effects other than cancer in an all-women sample of workers occupationally exposed to oil mists in the U.S. [42-44]. However, there were some limitations to the study. The analysis was limited by its small sample size due in part to the scarcity of mothers exposed to oil mists in NBDPS and the rarity of birth defects in an exposed working population. Small sample sizes yield large confidence intervals and low power. Small sample sizes also limited the ability to control for potential confounders, making residual confounding a potential explanation for the observed associations. Still, elevated association patterns were observed among several CHDs, and estimates were similar after controlling for a few covariates.

There is some potential for exposure misclassification due to the qualitative review of self-reported job characteristics and duties, especially if the details and dates reported about the jobs were insufficient or misremembered. However, the NBDPS design employed computer-assisted telephone interviews conducted by staff trained to record job histories in a standardized manner. Additionally, the timeframe for which jobs had to be recalled (i.e., before and during pregnancy) and the duration between dates of work and questionnaire administration were relatively short, likely reducing misclassification. Industrial hygiene sampling and biomarker exposure measures were not collected, meaning that it was not possible to assess the accuracy of the oil mist exposure assessment by expert raters. However, the review was conducted by an expert panel, and the inter-rater reliability for oil mist exposure assessment was high, minimizing the risk for misclassification [17]. We did not have enough detail regarding exposure to identify specific compounds within or co-occurring with oil mists that could cause reproductive toxicity. Lastly, the lack of paternal exposure information in our study could have led to (1) the potential misclassification of mothers who had working exposed partners, which could have caused the take-home exposure of mothers, and (2) an inability to consider the effects of paternal-mediated reproductive toxicity.

\section{Conclusions}

Results from the current study are consistent with previous studies finding associations between oil mist exposure and congenital heart defects, and provide additional evidence to suggest that oil mists could be a reproductive hazard. Future studies could clarify both maternally and paternally mediated mechanisms of reproductive toxicity. Further research is needed to evaluate for reproductive effects of occupational exposures to oil mists to inform occupational safety and health practices, particularly for 
pregnant workers, workers looking to become pregnant, and working partners of women who are pregnant or planning pregnancy.

Supplementary Materials: The following are available online at http:/www.mdpi.com/1660-4601/16/9/1560/s1: Table S1: Demographic characteristics of mothers occupationally exposed and unexposed to oil mists in early pregnancy, NBDPS 1997-2011, Table S2: Crude and adjusted associations between maternal occupational oil mist exposure in early pregnancy and (simple) isolated or multiple birth defects, NBDPS 1997-2011.

Author Contributions: M.S. conducted the analyses and drafted the manuscript. C.M.R. coordinated occupational exposure assessment. C.Y.J. assisted with statistical analyses and duplication. C.M.R., C.Y.J., M.A.W., C.C.L., T.R.-C., and J.R. provided subject matter expertise and assisted with the study design, interpretation of results, and manuscript review. T.N.B.D.P.S. supported data collection, manuscript review, and approved the manuscript to be published.

Funding: This work was supported through cooperative agreements under PA 96043, PA 02081 and FOA DD09-001 from the Centers for Disease Control and Prevention to the Centers for Birth Defects Research and Prevention participating in the National Birth Defects Prevention Study. This work was additionally supported by contract 200-2000-08018 from the Centers for Disease Control and Prevention and the National Institute for Occupational Safety and Health.

Acknowledgments: The authors thank all Centers that participated in the National Birth Defects Prevention Study. The findings and conclusions in this report are those of the authors and do not necessarily represent the official position of the Centers for Disease Control and Prevention.

Conflicts of Interest: The authors declare no conflicts of interest.

\section{References}

1. Lawson, C.C.; Bloom, T.F.; Hein, M.J. NIOSH Health Hazard Evaluation Report: HETA \#99-0343-2882 Thomas Steel Strip Corporation, Warren, Ohio. November 2002. Available online: https://www.cdc.gov/ niosh/hhe/reports/pdfs/1999-0343-2882.pdf (accessed on 28 February 2019).

2. Edmonds, L.D.; James, L.M. Temporal trends in the prevalence of congenital malformations at birth based on the birth defects monitoring program, United States, 1979-1987. MMWR. Morb. Mortal. Wkly. Rep. 1990, 39, $19-23$.

3. ACGIH. Oil mist, mineral. In Documentation of the Threshold Limit Values and Biological Exposure Indices; American Conference of Governmental Industrial Hygienists: Cincinnati, OH, USA, 2001.

4. Simpson, A.T.; Stear, M.; Groves, J.A.; Piney, M.; Bradley, S.D.; Stagg, S.; Crook, B. Occupational exposure to metalworking fluid mist and sump fluid contaminants. Ann. Occup. Hyg. 2003, 47, 17-30.

5. NIOSH. What You Need to Know about Occupational Exposure to Metalworking Fluids: DHHS (NIOSH) Publication No. 98-116. 1998. Available online: https://www.cdc.gov/niosh/docs/98-116/default.html (accessed on 3 May 2019).

6. NIOSH. Criteria for a Recommended Standard: Occupational Exposure to Metalworking Fluids: DHHS (NIOSH) Publication No. 98-102. Cincinnati, OH, USA, 1998. Available online: https: //www.cdc.gov/niosh/docs/98-102/default.html (accessed on 3 May 2019).

7. CONCAWE. Health Aspects of Worker Exposure to Oil Mists; CONCAWE: Brussels, Blegium, 1986.

8. Fear, N.T.; Hey, K.; Vincent, T.; Murphy, M. Paternal occupation and neural tube defects: A case-control study based on the Oxford Record Linkage Study register. Paediatr. Perinat. Epidemiol. 2007, 21, 163-168. [CrossRef]

9. Tikkanen, J.; Heinonen, O.P. Occupational risk factors for congenital heart disease. Int. Arch. Occup. Environ. Health 1992, 64, 59-64. [CrossRef] [PubMed]

10. Tikkanen, J.; Heinonen, O.P. Risk factors for coarctation of the aorta. Teratology 1993, 47, 565-572. [CrossRef] [PubMed]

11. Lorente, C.; Cordier, S.; Bergeret, A.; De Walle, H.E.; Goujard, J.; Ayme, S.; Knill-Jones, R.; Calzolari, E.; Bianchi, F. Maternal occupational risk factors for oral clefts. Occupational Exposure and Congenital Malformation Working Group. Scand. J. Work Environ. Health 2000, 26, 137-145. [CrossRef] [PubMed]

12. Yoon, P.W.; Rasmussen, S.A.; Lynberg, M.C.; Moore, C.A.; Anderka, M.; Carmichael, S.L.; Costa, P.; Druschel, C.; Hobbs, C.A.; Romitti, P.A.; et al. The National Birth Defects Prevention Study. Public Health Rep. 2001, 116 (Suppl. 1), 32-40. [CrossRef] 
13. Reefhuis, J.; Gilboa, S.M.; Anderka, M.; Browne, M.L.; Feldkamp, M.L.; Hobbs, C.A.; Jenkins, M.M.; Langlois, P.H.; Newsome, K.B.; Olshan, A.F.; et al. The National Birth Defects Prevention Study: A review of the methods. Birth Defects Res. A. Clin. Mol. Teratol. 2015, 103, 656-669. [CrossRef] [PubMed]

14. Rasmussen, S.A.; Olney, R.S.; Holmes, L.B.; Lin, A.E.; Keppler-Noreuil, K.M.; Moore, C.A. Guidelines for case classification for the National Birth Defects Prevention Study. Birth Defects Res. A Clin. Mol. Teratol. 2003, 67, 193-201. [CrossRef] [PubMed]

15. Ailes, E.C.; Gilboa, S.M.; Riehle-Colarusso, T.; Johnson, C.Y.; Hobbs, C.A.; Correa, A.; Honein, M.A. Prenatal diagnosis of nonsyndromic congenital heart defects. Prenat. Diagn. 2014, 34, 214-222. [CrossRef] [PubMed]

16. Botto, L.D.; Lin, A.E.; Riehle-Colarusso, T.; Malik, S.; Correa, A. Seeking causes: Classifying and evaluating congenital heart defects in etiologic studies. Birth Defects Res. A. Clin. Mol. Teratol. 2007, 79, 714-727. [CrossRef]

17. Rocheleau, C.M.; Lawson, C.C.; Waters, M.A.; Hein, M.J.; Stewart, P.A.; Correa, A.; Echeverria, D.; Reefhuis, J. Inter-rater reliability of assessed prenatal maternal occupational exposures to solvents, polycyclic aromatic hydrocarbons, and heavy metals. J. Occup. Environ. Hyg. 2011, 8, 718-728. [CrossRef] [PubMed]

18. Herdt-Losavio, M.L.; Lin, S.; Chapman, B.R.; Hooiveld, M.; Olshan, A.; Liu, X.; DePersis, R.D.; Zhu, J.; Druschel, C.M. Maternal occupation and the risk of birth defects: An overview from the National Birth Defects Prevention Study. Occup. Environ. Med. 2010, 67, 58-66. [CrossRef]

19. Hackshaw, A.; Rodeck, C.; Boniface, S. Maternal smoking in pregnancy and birth defects: A systematic review based on 173,687 malformed cases and 11.7 million controls. Hum. Reprod. Update 2011, 17, 589-604. [CrossRef]

20. Suhl, J.; Romitti, P.A.; Rocheleau, C.; Cao, Y.; Burns, T.L.; Conway, K.; Bell, E.M.; Stewart, P.; Langlois, P. Parental occupational pesticide exposure and nonsyndromic orofacial clefts. J. Occup. Environ. Hyg. 2018, 15, 641-653. [CrossRef]

21. Pettigrew, S.M.; Bell, E.M.; Van Zutphen, A.R.; Rocheleau, C.M.; Shaw, G.M.; Romitti, P.A.; Olshan, A.; Lupo, P.J.; Soim, A.; Makelarski, J.A.; et al. Paternal and joint parental occupational pesticide exposure and spina bifida in the National Birth Defects Prevention Study, 1997 to 2002. Birth Defects Res. A Clin. Mol. Teratol. 2016, 106, 963-971. [CrossRef]

22. Schnitzer, P.G.; Olshan, A.F.; Savitz, D.A.; Erickson, J.D. Validity of mother's report of father's occupation in a study of paternal occupation and congenital malformations. Am. J. Epidemiol. 1995, 141, 872-877. [CrossRef]

23. Plunkett, M.D.; Harvey, B.A.; Kochilas, L.K.; Menk, J.S.; St Louis, J.D. Management of an associated ventricular septal defect at the time of coarctation repair. Ann. Thorac. Surg. 2014, 98, 1412-1418. [CrossRef] [PubMed]

24. Bureau of Labor Statistics. Employed persons by detailed industry, sex, race, and Hispanic or Latino ethnicity. 2018. Available online: https://www.bls.gov/cps/cpsaat18.htm (accessed on 3 May 2019).

25. Nguyen, R.H.; Wilcox, A.J.; Moen, B.E.; McConnaughey, D.R.; Lie, R.T. Parent's occupation and isolated orofacial clefts in Norway: A population-based case-control study. Ann. Epidemiol. 2007, 17, 763-771. [CrossRef] [PubMed]

26. Bureau of Labor Statistics. Employed Persons by Detailed Occupation, Sex, Race, and Hispanic or Latino Ethnicity. 2018. Available online: https://www.bls.gov/cps/cpsaat11.htm (accessed on 3 May 2019).

27. Bianchi, F.; Cianciulli, D.; Pierini, A.; Seniori Costantini, A. Congenital malformations and maternal occupation: A registry based case-control study. Occup. Environ. Med. 1997, 54, 223-228. [CrossRef] [PubMed]

28. Garcia, A.M.; Fletcher, T. Maternal occupation in the leather industry and selected congenital malformations. Occup. Environ. Med. 1998, 55, 284-286. [CrossRef]

29. Vrijheid, M.; Armstrong, B.; Dolk, H.; van Tongeren, M.; Botting, B. Risk of hypospadias in relation to maternal occupational exposure to potential endocrine disrupting chemicals. Occup. Environ. Med. 2003, 60, 543-550. [CrossRef]

30. Seitz, T.; Barron, S. NIOSH Health Hazard Evaluation Report: HETA \#87-349-2022 Rockcastle Manufacturing, Mount Vernon, Kentucky. Available online: https://www.cdc.gov/niosh/nioshtic-2/00194425.html (accessed on 28 February 2019).

31. Friesen, M.C.; Park, D.U.; Colt, J.S.; Baris, D.; Schwenn, M.; Karagas, M.R.; Armenti, K.R.; Johnson, A.; Silverman, D.T.; Stewart, P.A. Developing estimates of frequency and intensity of exposure to three types of metalworking fluids in a population-based case-control study of bladder cancer. Am. J. Ind. Med. 2014, 57, 915-927. [CrossRef] 
32. NIOSH. Oil mist (mineral). NIOSH Pocket Guide to Chemical Hazards, U.S. Department of Health and Human Services, Public Health Service, Centers for Disease Control and Prevention, National Institute for Occupational Safety and Health Cincinnati, OH; 2016. Available online: https://www.cdc.gov/niosh/npg/ npgd0472.html (accessed on 3 May 2019).

33. Negm, N.A.; Kailas, S.V.; Pottirayil, A.; Abd-Elaal, A.A. Use of surfactants in metal cutting fluids formation. In Surfactants in Tribology; Biresaw, G., Mittal, K.L., Eds.; CRC Press: Boca Raton, FL, USA, 2014.

34. International Agency for Research on Cancer. Trichloroethylene, Tetrachloroethylene, and Some Other Chlorinated Agents. In IARC Monographs on the Evaluation of Carcinogenic Risks to Humans; International Agency for Research on Cancer: Lyon, France, 2014.

35. Van Tongeren, M.; Nieuwenhuijsen, M.J.; Gardiner, K.; Armstrong, B.; Vrijheid, M.; Dolk, H.; Botting, B. A job-exposure matrix for potential endocrine-disrupting chemicals developed for a study into the association between maternal occupational exposure and hypospadias. Ann. Occup. Hyg. 2002, 46, 465-477. [PubMed]

36. Birks, L.; Casas, M.; Garcia, A.M.; Alexander, J.; Barros, H.; Bergstrom, A.; Bonde, J.P.; Burdorf, A.; Costet, N.; Danileviciute, A.; et al. Occupational exposure to endocrine-disrupting chemicals and birth weight and length of gestation: A European meta-analysis. Environ. Health Perspect. 2016, 124, 1785-1793. [CrossRef] [PubMed]

37. Langlois, P.H.; Hoyt, A.T.; Lupo, P.J.; Lawson, C.C.; Waters, M.A.; Desrosiers, T.A.; Shaw, G.M.; Romitti, P.A.; Lammer, E.J. Maternal occupational exposure to polycyclic aromatic hydrocarbons and risk of neural tube defect-affected pregnancies. Birth Defects Res. A Clin. Mol. Teratol. 2012, 94, 693-700. [CrossRef]

38. Naufal, Z.; Zhiwen, L.; Zhu, L.; Zhou, G.D.; McDonald, T.; He, L.Y.; Mitchell, L.; Ren, A.; Zhu, H.; Finnell, R.; et al. Biomarkers of exposure to combustion by-products in a human population in Shanxi, China. J. Expo Sci. Environ. Epidemiol. 2010, 20, 310-319. [CrossRef] [PubMed]

39. Ren, A.; Qiu, X.; Jin, L.; Ma, J.; Li, Z.; Zhang, L.; Zhu, H.; Finnell, R.H.; Zhu, T. Association of selected persistent organic pollutants in the placenta with the risk of neural tube defects. Proc. Natl. Acad. Sci. USA 2011, 108, 12770-12775. [CrossRef]

40. Lupo, P.J.; Langlois, P.H.; Reefhuis, J.; Lawson, C.C.; Symanski, E.; Desrosiers, T.A.; Khodr, Z.G.; Agopian, A.J.; Waters, M.A.; Duwe, K.N.; et al. Maternal occupational exposure to polycyclic aromatic hydrocarbons: effects on gastroschisis among offspring in the National Birth Defects Prevention Study. Environ. Health Perspect. 2012, 120, 910-915. [CrossRef]

41. Fuchs, J.; Burg, J.; Hengstler, J.G.; Bolm-Audorff, U.; Oesch, F. DNA damage in mononuclear blood cells of metal workers exposed to N-nitrosodiethanolamine in synthetic cutting fluids. Mutat. Res. 1995, 342, 95-102. [CrossRef]

42. Betenia, N.; Costello, S.; Eisen, E.A. Risk of cervical cancer among female autoworkers exposed to metalworking fluids. Scand. J. Work Environ. Health 2012, 38, 78-83. [CrossRef] [PubMed]

43. Friesen, M.C.; Betenia, N.; Costello, S.; Eisen, E.A. Metalworking fluid exposure and cancer risk in a retrospective cohort of female autoworkers. Cancer Causes Control 2012, 23, 1075-1082. [CrossRef] [PubMed]

44. Garcia, E.; Bradshaw, P.T.; Eisen, E.A. Breast cancer incidence and metalworking fluid exposure in a cohort of female autoworkers. Am. J. Epidemiol. 2017. [CrossRef] [PubMed]

(C) 2019 by the authors. Licensee MDPI, Basel, Switzerland. This article is an open access article distributed under the terms and conditions of the Creative Commons Attribution (CC BY) license (http://creativecommons.org/licenses/by/4.0/). 